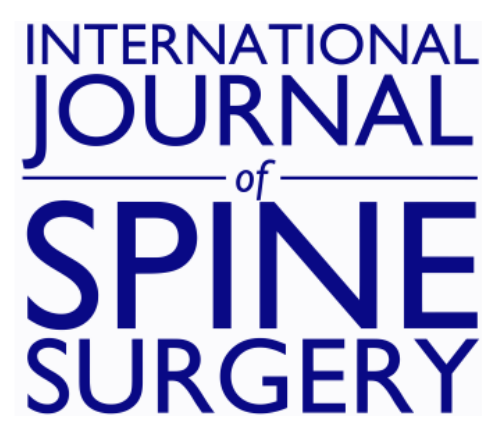

\title{
ISASS Policy Statement - Cervical Artificial Disc
}

Domagoj Coric

Int J Spine Surg 2014, 8 ()

doi: https://doi.org/10.14444/1006

http://ijssurgery.com/content/8/6

This information is current as of April 26, 2023.

Email Alerts Receive free email-alerts when new articles cite this article. Sign up at: http://ijssurgery.com/alerts 


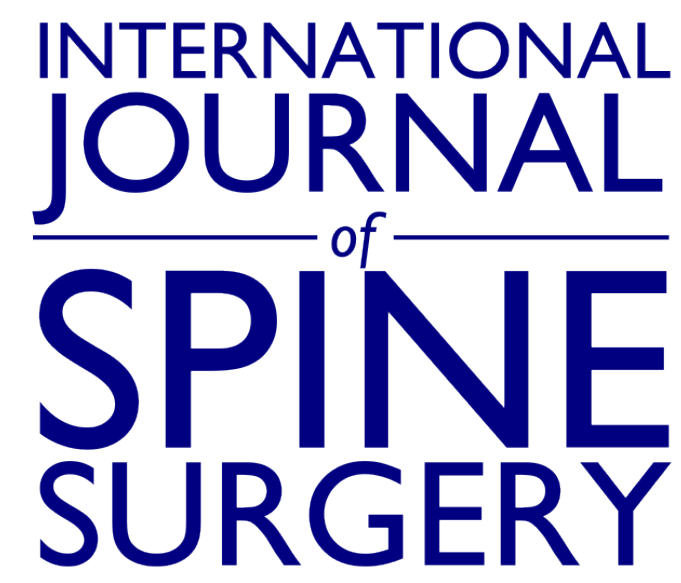

This article generously published free of charge by the International Society for the Advancement of Spine Surgery.

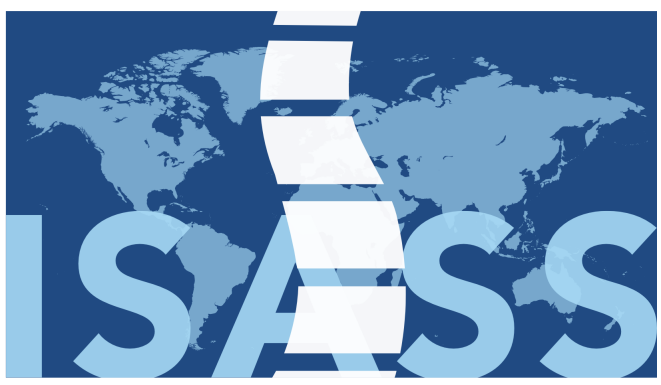

INTERNATIONAL SOCIETY for the ADVANCEMENT of SPINE SURGERY 


\section{ISASS Policy Statement - Cervical Artificial Disc}

Domagoj Coric, $M D$

Department of Neurosurgery, Carolinas Medical Center, Charlotte, NC USA

\section{Introduction}

Morgan Lorio, MD, FACS, Chair, ISASS Task Force on Coding \& Reimbursement

The ISASS Task Force reached out to Domagoj Coric, MD to provide a timely summation on cervical disc arthroplasty given his special interest and recent IASP championship of this innovative technology to insure enhanced spine patient access. The ISASS Task Force is pleased with this step towards published ISASS societal policy and applauds Dr. Coric's effort; if ISASS is to continue to succeed we must continually harness the voluntary talents and energies of our members with gratitude.

keywords: policy

Volume 8 Article 6 doi: 10.14444/1006

\section{Background}

Cervical total disc replacement (cTDR) was first introduced in Europe in the late 1990s. ${ }^{1}$, 2, 3, 4 Subsequently, three prospective, randomized Food and Drug Administration (FDA) regulated Investigational Device Exemption (IDE) trials were initiated in the US dating back to $2000 .^{5,6,7}$ These initial IDE studies ultimately led to the first three FDA approvals for cTDR devices in the US, Prestige $\mathrm{ST}^{5}$ (Medtronic- 541 patients, 32 sites) (2007), Prodisc-C ${ }^{6}$ (Depuy Synthes- 209 patients, 13 sites) (2008) and Bryan Disc ${ }^{7}$ (Medtronic- 463 patients, 30 sites) (2009), for the treatment of 1-level cervical spondylosis from C3-7. There have been an additional three FDA approvals, Secure-C $\mathrm{C}^{8}$ (Globus Medical- 380 patients, 18 sites), $\mathrm{PCM}^{9}$ (Nuvasive- 342 patients, 24 sites) (2012) and Mobi-C ${ }^{10}$ (LDR- 1level: 260 patients, 24 sites; 2 level: 339 patients) (2013). There has also been a new indication as Mobi-C was also approved for treatment of two-level cervical spondylosis $\mathrm{C} 3-7 .{ }^{10}$

All the US FDA IDE trials compared cTDR devices to standard anterior discectomy and fusion (ACDF) in prospective and randomized studies producing Level 1 data. As with all industry-sponsored studies, bias, both investigator and patient related, is a concern. This concern was somewhat mitigated by the fact that these IDE studies have cumulatively involved over 2,500 patients at over 100 study sites (Table 1). Furthermore, these studies utilized similar validated outcome measures including Neck Disability Index (NDI), Visual Analog Scale (VAS) and SF-36. ACDF is an established surgical procedure with a 
well-documented safety and efficacy dating back 60 years. ${ }^{11,12,13,14}$ Cervical arthroplasty offers some theoretical advantages over ACDF. ${ }^{15,16,17}$. ACDF results in loss of motion at the index level(s), placing increased stress on adjacent levels above and below the fusion. ${ }^{18,19,20,21,22,23,24,25,26,27}$ There is a documented incidence of clinically symptomatic adjacent-level disc disease following ACDF ranging from 0.5-3\% annually. ${ }^{13,14,28}$ Hilibrand et al. ${ }^{20}$ reported a rate of symptomatic adjacent-level degeneration following ACDF of $2.9 \%$ annually, although the rate of adjacent level reoperation was only $0.7 \%$ per year. Similarly, Robertson and associates reported a symptomatic adjacent-segment degenerative disc disease rate of $7 \%$ in the anterior fusion series. By preserving motion at the operated level, cTDR has the potential to positively affect the occurrence of adjacent segment degeneration. ${ }^{29,30,31,32}$

Table 1. FDA-approved cTDR devices with number of patients enrolled in pivotal IDE study.

\begin{tabular}{|l|l|}
\hline cTDR Device & \# of Patients \\
\hline Prestige ST & 541 \\
\hline Prodisc-C & 209 \\
\hline Bryan Disc & 463 \\
\hline Secure-C & 380 \\
\hline PCM & 342 \\
\hline Mobi-C 1-level & 260 \\
\hline Mobi-C 2-level & 339 \\
\hline TOTAL & 2534 \\
\hline
\end{tabular}

In order to establish an evidence based rationale for cTDR as a viable therapeutic modality in the treatment of cervical radiculopathy, cervical artificial discs must satisfy several criteria. They must show clinical efficacy and safety through the regulatory IDE process and receive the appropriate regulatory approval. Additionally, cervical arthroplasty must validate that the technique maintains segmental motion with concomitant decreased adjacent level stresses compared to ACDF. Furthermore, the results of multi-center controlled studies should be replicated at individual centers. Intermediate term data should reaffirm safety and efficacy beyond the two year follow-up mandated by FDA IDE process. Once accepted as reasonable treatment option, long-term data should be utilized to refine ideal indications for that procedure. ${ }^{33}$

\section{Results}

The results of seven different prospective, randomized studies have been published in peer-reviewed literature. $5,6,7,8,10,34,35$ These studies, comparing cTDR to standard anterior cervical discectomy and fusion (ACDF), have shown positive results for cTDR leading to six different FDA approvals. Although the statistical design of these studies was "non-inferiority." on numerous clinical end-points, artificial discs were found to be statistically superior to fusion. Mummaneni and colleagues showed statistically significant higher neurological success for the Prestige ST artificial disc. ${ }^{6}$ Heller et al and 
Coric et al documented statistically significant greater overall composite success rates for Bryan and Kineflex $\mid \mathrm{C}$, respectively. ${ }^{5,34}$ Davis and associates reported statistically superior overall success for 2-level surgery with Mobi-C. ${ }^{10}$ Murrey and associates reported statistically significant decrease in secondary surgeries following Prodisc-C placement. ${ }^{7}$ Vaccarro et al showed statistically superiority in favor of SECURE-C in terms of overall success, secondary surgery as well as patient satisfaction. ${ }^{8}$ Phillips et al reported statistically significant lower NDI scores and dysphagia rates as well as higher patient satisfaction for PCM. ${ }^{35}$

The composite overall success rate reported from the IDE studies favor arthroplasty over ACDF. The following cTDR devices showed greater composite overall success (Prestige ST 79\% vs $68 \%$; Prodisc-C $72 \%$ vs $68 \%$; Bryan $83 \%$ vs $73 \%$; Kineflex $\mid \mathrm{C} 85 \%$ vs $71 \%$; SECURE-C 84\% vs 73\%; PCM 75\% vs 65\%; Mobi-C 1-level 74\% vs 65\%, 2-level 70\% vs $37 \%$ )(Table 2). ${ }^{10,17,34,35,36,37,38}$

Table 2. Composite overall success rates from pivotal IDE study, cTDR versus ACDF.

\begin{tabular}{|l|l|l|}
\hline IDE study & $c T D R$ & $A C D F$ \\
\hline Prestige ST & $79 \%$ & $68 \%$ \\
\hline Prodisc-C & $72 \%$ & $68 \%$ \\
\hline Bryan Disc & $83 \%$ & $73 \%$ \\
\hline Secure-C & $84 \%$ & $73 \%$ \\
\hline PCM & $75 \%$ & $65 \%$ \\
\hline Mobi-C 1-level & $74 \%$ & $65 \%$ \\
\hline Mobi-C 2-level & $70 \%$ & $37 \%$ \\
\hline Kineflex/C & $85 \%$ & $71 \%$ \\
\hline
\end{tabular}

Range of motion data from the IDE studies confirm that cervical arthroplasty devices maintain segmental motion (in degrees) at the treated level: Prestige ST (7.7), Bryan (6.5), Prodisc-C (8.4), Kineflex|C (9.8), SECURE-C (9.7), PCM (5.7), Mobi-C 1-level (10.8) and 2-level $(10.1,8.3)$ (Table 3). ${ }^{10,17,34,35,36,37,38}$

Table 3. Range of motion (ROM) for cTDR devices from pivotal IDE study.

\begin{tabular}{|l|l|}
\hline IDE study & Mean ROM (degrees) \\
\hline Prestige ST & 7.7 \\
\hline Prodisc-C & 8.4 \\
\hline Bryan Disc & 6.5 \\
\hline Secure-C & 9.7 \\
\hline PCM & 5.7 \\
\hline Mobi-C 1-level & 10.8 \\
\hline Mobi-C 2-level & $10.1,8.3$ \\
\hline
\end{tabular}


The results of these multi-center studies have been replicated with single center results. ${ }^{1 \text {, }}$ 33, 39, 40 Coric demonstrated statistically higher overall success rates from a single institution utilizing three different cTDR devices. ${ }^{33}$ Jawahar also combined data from three separate cTDR devices and reported clinical equivalence between arthroplasty and fusion, but no change in adjacent level disease at two years. ${ }^{40}$ Garrido reported long-term outcomes for the Bryan disc from a single site which favored cTDR on NDI, VAS and fewer additional surgeries. ${ }^{39}$ Level 2 and 3 data from single sites outside the United States (OUS) have also shown positive clinical results. Goffin ${ }^{4}$ and $\mathrm{Kim}^{41}$ reported safety and efficacy with 1- and 2-level cervical arthroplasty using the Bryan disc. Bertagnoli ${ }^{15}$ and Beuurain ${ }^{42}$ also showed good results with Prodisc-C and Mobi-C, respectively, at two year follow-up.

Intermediate and long-term follow-up studies, ranging from 4- to10-years, have also been published. ${ }^{31,43,44,45,46}$ Burkus and associates reported statistically higher rate of disability (NDI) improvement at 3- and 5-years for cTDR with Prestige ST. They also showed a statistically lower rate of index level surgery for cTDR at 5-years. ${ }^{43}$ Similarly, Delamarter et al reported a statistically higher rate of VAS satisfaction at all time points out to 4-year follow-up for Prodisc-C cTDR over ACDF. They also reported a statistically lower rate of index level surgery for cTDR at four years. ${ }^{46}$ Zigler et al reaffirmed those positive results out to five year follow-up. ${ }^{45}$ Quan reported eight-year outcomes on the Bryan disc using Odom criteria and showed good/excellent results in $90 \%$ of patients. ${ }^{31}$ Coric et al reported that in both cTDR and ACDF groups, the mean NDI and VAS scores improved significantly by 6 weeks and remained significantly improved from 4- to 8-year follow-up. ${ }^{44}$

There is considerably less literature examining the use of cervical arthroplasty for multilevel cervical spondylosis. Several studies have reported positive results for cTDR in patients with 2-level disease. ${ }^{4,41,47}$ As previously discussed, Davis et $\mathrm{al}^{10}{ }^{10}$ reported Level 1 data from the prospective, randomized IDE study comparing 2-level cTDR with MobiC compared to 2-level ACDF. These authors reported dramatically improved overall success with arthroplasty ( $70 \%$ versus $37 \%$ ) over fusion.

Several meta-analyses examining cTDR performance have also been published. ${ }^{37,38,48,49}$ Bartels et al published a meta-analysis of six peer-reviewed articles and three meeting abstracts. These authors reported statistically superior results for cTDR in pain (VAS) and function (SF-36) at 12 months and disability (NDI) at 24 months, yet concluded that there was no proven clinical benefit for arthroplasty. ${ }^{48} \mathrm{McAfee}$ and associates combined the results of four separate IDE studies and reported statistical superiority for overall success, neurologic success and survivorship success for cTDR. ${ }^{37}$ Upadhyaya and co-authors combined the completed data sets from the first 3 FDA-approved cTDR devices and reported statistically significantly lower reoperation rate for adjacent level disease as well as superior neurological success. ${ }^{38}$

It is well understood that fusion sacrifices motion at the index level and places stresses on adjacent levels. $3,12,13,18,21,23,25,26,27,29,50,51,52$ The consequences of those stresses are much less understood. Adjacent level disease is likely a multifactorial process involving several disparate factors including natural history of the underlying disease process 
(spondylosis), surgical technique, patient selection and type of instrumentation employed. It is also well established that arthroplasty maintains motion decreases adjacent level

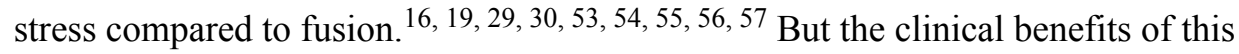
decreased stress remain debatable. ${ }^{34}$ It is important to differentiate between adjacent level degeneration (deterioration above or below the operative level evident on radiographic imaging) and adjacent level disease (clinically symptoms attributable to a level above or below the operative level). The only Level 1 studies to document statistically significant decrease in adjacent level disease for cervical arthroplasty are the previously discussed meta-analysis papers by McAfee ${ }^{37}$ and Upadhyaya. ${ }^{38}$ A decreased rate of adjacent deterioration from the IDE studies in favor of arthroplasty devices was reported by Coric $^{34}$ (9\% vs $\left.25 \%\right)$, Davis ${ }^{10}\left(11 \%\right.$ vs $23 \%$ ) and Vaccarro. ${ }^{8}$ Kim and associates also reported decreased degenerative change in patients treated with the Bryan artificial disc. ${ }^{40}$

There are several unique complications associated with cTDR devices including subsidence/dislocation, wear debris/osteolysis and heterotopic ossification. ${ }^{58,59,60,61}$ The published results of IDE studies generally show low rates of reoperation ${ }^{43,46}$ with the majority of these related to persistent neck pain without device failure. The rate of bridging heterotopic bone across these studies was also low, ranging from $0-3 \%$. $5,6,7,8$, 10,34

\section{Conclusion}

Anterior cervical discectomy and fusion has an established record of clinical and radiographic efficacy. ${ }^{12,14,27,62,63}$ The safety and efficacy of cervical arthroplasty has been established with a growing body of Level 1 evidence that is compelling enough to no longer consider cTDR investigational. ${ }^{33}$ This evidence is bolstered by experience with multiple devices, at multiple sites, in and out of the investigational setting and with short-, intermediate- and long-term follow-up. cTDR is a viable alternative to ACDF in select patients with symptomatic 1- and 2-level cervical radiculopathy or myelopathy (Table 4).

Table 4. Indications for cervical total disc replacement (cTDR).

Cervical arthroplasty is indicated in patients meeting the following criteria:

- Skeletally mature

- Clinically symptomatic cervical radiculopathy and/or myelopathy due to neural compression $\mathrm{C} 3-\mathrm{C} 7$ at one-level or two contiguous levels

- Failed at least 6 weeks of nonsurgical treatment or shows signs of progressively clinical deterioration

Clinically symptomatic pertains to one of the following:

- Intractable radiculopathy (arm pain and/or a neurological deficit) with or without associated neck pain

- Myelopathy (due to abnormality localized to the level of the disc space) 


\section{References}

1. Coric D, Finger F, Boltes P: The Bryan Cervical Disc prospective, randomized, controlled study: Early clinical results from a single investigational site. $\mathrm{J}$ Neurosurg-Spine 41:31-35, 2006

2. Goffin J, Casey A, Kehr P, Lebig K, Lind B, Logroscino C, et al: Preliminary clinical experience with the Bryan cervical disc prosthesis. Neurosurg 51:840-847, 2002

3. Goffin J, Geusens E, Vantomee N, Quintens E, Waerzeggers Y, Depreitere B, et al: Long-term follow-up after interbody fusion of the cervical spine. J Spin Disord Tech 17:79-85, 2004

4. Goffin J, Van Calenbergh F, van Loon J, Casey A, Kehr P, Liebig KE et al: Intermediate follow-up after treatment of degenerative disc disease with the Bryan cervical disc prosthesis: single-level and bi-level. Spine 23:2673-2678, 2003

5. Heller JG, Sasso RC, Papadopoulos SM, Anderson PA, Fessler RG, Hacker RJ, Coric D, Cauthen JC, Riew DK: Comparison of BRYAN Cervical Disc Arthroplasty With Anterior Cervical Decompression and Fusion. Spine 34:101-107, 2008

6. Mummaneni P, Burkus J, Haid R, Traynelis V, Zdeblick T: Clinical and radiographic analysis of cervical disc arthroplasty compared with allograft fusion: a randomized controlled clinical trial. J Neurosurg-Spine 6:198-200, 2007

7. Murrey D, Janssen M, Delamarter R, Goldstein J, Zigler J, et al: Results of the prospective, randomized controlled multicenter Food and Drug Administration investigational device exemption study of the ProDisc-C total disc replacement versus anterior discectomy and fusion for the treatment of 1-level symptomatic cervical disc disease. Spine J 9:275-286, 2009

8. Vaccaro A, Beutler W, Peppelman W, et al: Clinical outcomes with selectively constrained SECURE-C cervical disc arthroplasty: Two-year results from a prospective, randomized, controlled, multicenter Investigational Device Exemption study. Spine 38:2227-2239, 2013

9. Phillips F, Lee J, Geisler F, et al: A prospective, randomized, controlled clinical investigation comparing PCM cervical disc arthroplasty with anterior cervical discectomy and fusion. 2 year results from the US FDA IDE clinical trial. Spine 38:E907-918, 2013

10. Davis RJ, Kim KD, Hisey MS, et al: Cervical total disc replacement with Mobi$C \circledR$ cervical artificial disc versus anterior discectomy and fusion for the treatment of two-level symptomatic degenerative disc disease: a prospective, randomized, controlled multicenter clinical trial. J Neurosurg-Spine 19:532-545, 2013

11. Aronson N, Filtzer D, Bagan M: Anterior cervical fusion by the Smith-Robinson approach. J Neurosurg 29:396-404, 1968

12. Bohlman HH, Emery SE, Goodfellow DB, Jones PK: Robinson anterior cervical discectomy and arthrodesis for cervical radiculopathy. Long-term follow-up of one hundred and twenty-two patients. JBJS-A 75:1298-1307, 1993

13. Gore DR, Sepic SB: Anterior cervical fusion for degenerated or protruded discs: a review of one hundred and forty-six patients. Spine 9:667-671, 1984 
14. Smith GW, Robinson RA: The treatment of certain cervical spine disorders by anterior removal of the intervertebral disc and interbody fusion. JBJS(A) 40:607-624, 1958

15. Bertagnoli R, Yue J, Pfeiffer F, Fenk-Mayer A, Lawrence J, Kershaw T, et al: Early results after Prodisc-C cervical disc replacement. J Neurosurg-Spine 2:403-410, 2005

16. DiAngelo D, Roberston J, Metcalf N, McVay B, Davis R: Biomechanical testing of an artificial cervical joint and an anterior cervical plate. J Spinal Disord Tech 16(4):314-323, 2003

17. Mummaneni $P$, Haid R. The future in the care of the cervical spine: interbody fusion and arthroplasty. J Neurosurg-Spine 2:155-159, 2004

18. Baba H, Furusawa N, Imura S, Kawaharea N, Tsuchiya H, Tomita K: Late radiographic findings after anterior cervical fusion for spondylotic myeloradiculopathy. Spine 18:2167-2173, 1993

19. Eck JC, Humphreys SC, Lim TH, Jeong ST, Kim JG, Hodges SD, et al.: Biomechanical study on the effect of cervical spine fusion on adjacent intradiscal pressure and segmental motion. Spine 27:2431-2434, 2002

20. Hilibrand A, Carlson G, Palumbo M, Jones P, Bohlman H: Radiculopathy and myelopathy at segments adjacent to the site of a previous anterior cervical arthrodesis. J Bone Joint Surg(A) 81:519-528, 1999

21. Kulkarni V, Rajshekhar V, Raghuram L: Accelerated spondylotic changes adjacent to the fused segment following central cervical corpectomy: magnetic resonance imaging study evidence. J Neurosurg 100(1 Suppl):2-6, 2004

22. Matsunaga S, Kabayama S, Yamamoto T, Yone K, Sakou T, Nakanishi K: Strain on intervertbral discs after anterior cervical decompression and fusion. Spine 24:670-675, 1999

23. Pospiech J, Stolke D, Wilke H, Claes L: Intradiscal pressure recordings in the cervical spine. Neurosurg 44:379-385, 1999

24. Wang J, McDonough P, Endow K, Kanin L, Delamarter R: The effect of cervical plating on single-level anterior cervical discectomy and fusion. J Spinal Disord 112:467-471, 1999

25. Weinhoffer SL, Guyer RD, Herbert M, Griffith SL: Intradiscal pressure measurements above an instrumented fusion. A cadaveric study. Spine 20:526-531, 1995

26. Wigfield C, Skrzypiec D, Jackowski A, Adams M: Internal stress distribution in cervical intervertebral discs: the influence of an artificial cervical joint and simulated anterior interbody fusion. J Spinal Disord Tech 16:441-449, 2003

27. Yue WM, Brodner W, Highland TR: Long-term results after anterior cervical discectomy and fusion with allograft and plating: a 5- to 11-year radiologic and clinical follow-up study. Spine 30:2138-44, 2005

28. Fountas FN, Kapalaki EZ, Nikolakakos LG, Smisson HF, Johnston KW, Grigoriam AA, Lee GP, Robinson JS: Anterior cervical discectomy and fusion associated complications. Spine 32:2310-2317, 2007

29. Chang U-K, Kim DH, Lee MC, Willenberg R, Kim S-H, Lim J: Changes in adjacent-level disc pressure and facet joint force after cervical arthroplasty compared with cervical discectomy and fusion. J Neurosurg-Spine 7:33-39, 2007 
30. Dmitriev AE,Cunningham BW,Hu N,Sell G,Vigan F,McAfee PC: Adjacent level intradiscal pressure and segmental kinematics following a cervical total arthroplasty: an in vitro human cadaveric model. Spine 30:1165-1172, 2005

31. Quan G, Vital J, Hansen S, et al: Eight-year clinical and radiological follow-up of the Bryan cervical disc arthroplasty. Spine 36:639-646, 2011

32. Robertson JT, Papadopoulos SM, Traynelis VC: Assessment of adjacent-segment disease in patients treated with cervical fusion or arthroplasty: a prospective 2-year study. J Neurosurg-Spine3:417-423, 2005

33. Coric D, Cassis J, Carew JD, Boltes MO: Prospective Study of Cervical Arthroplasty: 98 Patients from Three Separate IDE Studies from a Single Investigational Site with Minimum Two Year Follow-up. J Neurosurg-Spine 13:715-721, 2010

34. Coric D, Nunley P, Guyer RD, et al: Prospective, randomized, multicenter study of cervical arthroplasty: 269 patients from the Kineflex ${ }^{\circledR} \mid \mathrm{C}$ artificial disc IDE study with minimum two year follow-up. J Neurosurg-Spine 15:348-358, 2011

35. Phillips FM, Allen TR, Regan JJ, Albert TJ, Cappuccino A, Devine JG, Ahrens JE, Hipp JA, McAfee PC: Cervical disc replacement in patients with and without previous adjacent level fusion surgery: a prospective study. Spine 34:556-565, 2009

36. Fraser JF, Hartl R: Anterior approaches to fusion of the cervical spine a metaanalysis of fusion rates. J Neurosurg Spine 6:298-303, 2007

37. McAfee PC, Reah C, Gilder K, Eisermann L, Cunningham B: A meta-analysis of comparative outcomes following cervical arthroplasty or anterior cervical discectomy and fusion: results from 4 prospective multicenter randomized clinical trial and up to 1226 patients. Spine 37:943-952, 2012

38. Upadhyaya CD, Wu JC, Haid RW, et al: Analysis of the three US FDA-IDE cervical arthroplasty trials. J Neurosurg-Spine 16:216-228, 2012

39. Garrido BJ, Taha TA, Sasso RC: Clinical outcomes of Bryan cervical disc arthroplasty a prospective, randomized, controlled, single site trial with 48-month follow-up. J Spinal Disord Tech 23:367-371, 2010

40. Jawahar A, Cavanaugh D, Kerr E, Birdsong E, Nunley P: Total disc arthroplasty does not affect the incidence of adjacent segment degeneration in cervical spine: results of 93 patients in three prospective randomized clinical trials. Spine J 10:1043-1048, 2010

41. Kim SW, Limson MA, Kim SB, Arbatin JJ, Chang KY, Park MS et al: Comparison of radiographic changes after ACDF versus Bryan disc arthroplasty in single and bi-level cases. Eur Spine J 18:218-231, 2009

42. Beaurain J, Bernard P, Dufour T, Fuentes J, Hovorka I, et al: Intermediate clinical and radiological results of cervical TDR (Mobi-C) with up to 2 years of followup. Eur Spine J 18:841-850, 2009

43. Burkus JK, Haid RW, Traynelis VC, and Mummaneni PV: Long-clinical and radiographic outcomes of cervical disc replacement with the Prestige disc: results from a prospective randomized controlled clinical trial. J Neurosurg-Spine 13:308-318, 2010

44. Coric D, Kim PK, Clemente J, Boltes MO, Nussbaum M, James S: Prospective, randomized study of cervical arthroplasty and ACDF with long-term follow-up: 
74 patients from a single site with four- to eight-year follow-up. J NeurosurgSpine 18:85-95, 2013

45. Zigler JE, Delamarter RB, Murrey D, Spivak J, Janssen M: ProDisc-C and ACDF as surgical treatment for single level cervical symptomatic degenerative disc disease: Five-year results of an FDA study. Spine 38:203-209, 2013

46. Delamarter RB, Murrey D, Janssen ME, Goldstein JA, Zigler J, Tay BKB: Results at 24 months from the prospective, randomized, multicenter Investigational Device Exemption trial of Prodisc-C versus anterior cervical discectomy and fusion with 4-year follow-up and continued assess patients. IJSS 4:122-128, 2010

47. Huppert J, Beaurain J, Steib J, Bernard P, Dufour T, et al: Comparison between single- and multi-level patients: clinical and radiological outcomes 2 years after cervical disc replacement. Eur Spine J 20:1417-1426, 2011

48. Bartels R, Donk R, Verbeek A: No justification for cervical disk prostheses in clinical practice: a meta-analysis of randomized controlled trials. Neurosurg 66:1153-1160, 2010

49. Gao Y, Liu M, Li T, Huang F, Tang T, Xiang Z: A meta-analysis comparing the results of cervical disc arthroplasty with anterior cervical discectomy and fusion (ACDF) for the treatment of symptomatic cervical disc disease. J Bone \& Joint Surg Am 95:555-61, 2013

50. Hunter L, Braunstein E, Bailey R: Radiographic changes following anterior cervical fusion. Spine 5:399-401, 1980

51. Ishihara H, Kanamori M, Kawaguchi Y, Nakamura H, Kimura T: Adjacent segment disease after anterior cervical interbody fusion. Spine J 4:624-8, 2004

52. Reitman CA, Hipp JA, Nguyen L, Esses SI: Changes in segmental intervertebral motion adjacent to cervical arthrodesis: a prospective study. Spine 29:E221-6, 2004

53. Cunningham BW, Hu N, Zorn CM, McAfee PC: Comparative fixation methods of cervical disc arthroplasty versus conventional methods of anterior cervical arthrodesis: serration, teeth, keels, or screws? J Neurosurg Spine 12:214-220, 2010

54. Park DK, Lin EL, Phillips FM. Index and adjacent level kinematics after cervical disc replacement and anterior fusion: in vivo quantitative radiographic analysis. Spine 36:721-730, 2011

55. Puttlitz CM, Rousseau MA, Xu Z, Hu S, Tay BK, Lotz JC: intervertebral disc replacement maintains cervical spine kinetics. Spine 29:2809-14, 2004

56. Rabi D, Bertagnoli R, Wharton N, Pickett GE, Duggal N: Sagittal balance influences range of motion: an in vivo study with the ProDisc-C. Spine J 9:128-133, 2009

57. Wigfield C, Gill S, Nelson R, Langdon I, Metcalf N, Robertson JT: Influence of an artificial cervical joint compared with fusion on adjacent-level motion in the treatment of degenerative cervical disc disease. J Neurosurg-Spine 1:17-21, 2002

58. Bartels R, Donk R: Fusion around cervical disc prosthesis: case report. Neurosurg 57:194, 2005

59. Parkinson JF, Sekhon L: Cervical arthroplasty complicated by delayed spontaneous fusion: case report. J Neurosurg-Spine 2:377-380, 2005

60. Pickett GE, Sekhon LHS, Sears WR, Duggal N: Complications with cervical arthroplasty. J Neurosurg-Spine 4:98-105, 2006 
61. Sears WR, Duggal N, Sekhon LH, Williamson OD: Segmental malalignment with the Bryan cervical disc prosthesis--contributing factors. J Spinal Disord Tech20:111-117, 2007

62. Bailey RW, Badgley CE: Stabilization of the cervical spine by anterior fusion. JBJS-A 42:565-594, 1960

63. Cloward RB: The anterior approach for removal of ruptured cervical discs. J Neurosurg 15:602-617, 1958

\section{Corresponding Author}

Dr. Dom Coric, Email: dom@csna.com

\section{Disclosures}

Dr. Coric is a consultant to Pioneer Surgical, Medtronic, Globus Medical, Spine Motion, \& Spine Wave. He owns private stock in Spine Motion \& Spine Wave.

Copyright (C) 2014 ISASS - International Society for the Advancement of Spine Surgery. To see more or order reprints or permissions, see http://ijssurgery.com. 